\title{
CORREDORES VERDES URBANOS: ESTUDO DA VIABILIDADE DE CONEXÃO DAS ÁREAS VERDES DE VITÓRIA
}

\author{
URBAN GREEN CORRIDORS: STUDY OF THE VIABILITY OF CONNECTION OF OPEN \\ SPACES IN VITÓRIA
}

\author{
PENTEADO, Homero Marconi \\ MSc, MLA, Laboratório de Planejamento e Projetos, Universidade Federal do Espírito Santo,. \\ E-mail: homeropenteado@uol.com.br
}

\section{ALVAREZ, Cristina Engel de}

Dra., Laboratório de Planejamento e Projetos, Universidade Federal do Espírito Santo

E-mail: engel@npd.ufes.br

\section{RESUMO}

Grande parte dos profissionais de planejamento urbano tem buscado melhorar a qualidade de vida da população e a aplicação de princípios de sustentabilidade, que se refletem, na maioria dos casos, na busca de ampliação das áreas verdes, sejam na forma de parques, praças, arborização de vias ou mesmo incentivo aos jardins particulares. Esta pesquisa apresenta o resultado do estudo de viabilidade de criação de corredores verdes urbanos na cidade de Vitória, estabelecendo uma rede de conexões utilizando-se de sua malha viária, visando incrementar as condições ecológicas e paisagísticas urbanas e melhores condições de circulação de pedestres e ciclistas. Está alicerçada nos conceitos desenvolvidos pela ecologia da paisagem, baseada em fragmentos, corredores e matriz. A metodologia adotada foi aplicada em uma área teste, onde foram realizados levantamentos preliminares, mapeamento das áreas verdes, seleção de vias para implantação de corredores, avaliação dos possíveis corredores, inventário e análise das vias, diretrizes para estabelecimento dos corredores, ensaio projetual e criação de uma rede de corredores verdes. Dentre os principais resultados, verificou-se a possibilidade de criação de corredores com pequenas modificações nos perfis de vias que permitiriam a inserção de vegetação contínua, calçadas e ciclovias com consequências diretas (otimização das condições microclimáticas, melhoria na paisagem, atratividade para pequenos animais, incentivo ao percurso não motorizado, entre outros) e indiretas (redução das partículas em suspensão, redução dos níveis de ruído e do consumo de combustíveis etc.).

\section{Palavras-chave: Corredor, ecologia, paisagem, Vitória.}

\begin{abstract}
Urban planning professionals have applied sustainability principles, reflected on the increase of green space, parks, plazas, street trees etc. This research aims to explore the viability to create urban green corridors in Vitoria (ES), establishing a network of connections between its open spaces making use of its streets and avenues. The proposed corridors aim to improve urban ecology and landscape and the circulation of pedestrians and bikers. The study is based on landscape ecology concepts, for which the landscape is formed by fragments, corridors and matrix. An area was chosen as a test for the methodology adopted, which includes desk studies, mapping of green areas, selections of streets to create corridors, evaluation of street potential as green corridor, site inventory and analysis, definition of guidelines, design of scenarios, and establishment of a green corridor network for Vitória. As a result, it was verified that it is possible to create corridors with small changes on streets and sidewalks to allow continuous tree canopy and bikeways, with direct consequences (microclimates, image, attractiveness to small mammals and birds, incentive to use of bikes) and indirect (reduction of pollution and noise levels, consumption of fuel, etc.).
\end{abstract}

Key words: Corridors, ecology, landscape, Vitória. 


\section{Introdução}

Ao longo do processo de desenvolvimento de grande parte das cidades brasileiras, o adensamento urbano reservou poucos vazios que representassem oportunidades de lazer e preservação de recursos naturais. Os sítios disponíveis encontram-se isolados, cercados por ruas e avenidas que, por sua vez, possuem pouco espaço para pedestres, menos ainda para ciclistas e pequena possibilidade de arborização.

A pouca ocorrência de espaços verdes resulta em conseqüências diversas para a vida nas cidades. Ruas estreitas significam redução de ventilação natural, aumento de temperatura e concentração de polventes; ausência de vegetação acarreta menor sombreamento, maior quantidade de partículas polventes em suspensão no ar, menos habitats para pássaros, pequenos mamíferos, insetos ou répteis e, ainda, menor retenção e infiltração de águas da chuva.

O isolamento entre grandes espaços livres e demais áreas urbanas impossibilita a realização de uma rede que permita não somente maior conforto e incentivo para pedestres e ciclistas, como também a ocorrência de maior biodiversidade na cidade. Baschak \& Brown (1995) propõem um modelo de desenvolvimento de corredores verdes urbanos (CVUs) baseados em princípios de design ecológico e ecologia da paisagem. Cook (1991) sugere a criação de redes urbanas baseadas na ecologia da paisagem, compostas de sistemas de fragmentos de natureza e corredores interligados permeando a matriz urbana.

Vitória configura-se como uma das capitais brasileiras com grande potencial turístico, seja de lazer como de negócios e cuja ambiência, da mesma forma que atrai investimentos, determina a necessidade de estratégias específicas de planejamento. No entanto, verifica-se que as metodologias de planejamento urbano estão, quase sempre, alicerçadas nas malhas viárias e na resolução dos problemas decorrentes do crescimento urbano e do incremento populacional. Áreas destinadas à preservação são constantemente invadidas pela natural demanda habitacional; vias são abertas ou ampliadas para garantir o escoamento de veículos; áreas livres potenciais deixam de existir em conseqüência da necessidade de novos equipamentos e a paisagem natural fica diminuída frente à proliferação de novas edificações.

Experiências de implantação de CVUs vêm ocorrendo desde o século XIX, como por exemplo o Emerald Necklace de Olmsted, em Boston, até mais recentemente, como em Denver, onde se propõe conectar parques a escolas, centros de lazer e centros de bairro através de "ruas verdes" com ciclovias e calçadas contínuas, adequadas e arborizadas, seguras para a travessia de pedestres, acessíveis a pessoas de todas as idades e habilidades (Denver Parks and Recreation, 2003). Nas últimas décadas, iniciativas nos Estados Unidos, Canadá e Europa buscam desmontar esse cenário de isolamento através da "construção" de greenways (vias verdes) em escalas diversas, da local à transnacional.

No Brasil iniciativas isoladas abordam problemas ecológicos e urbanos, de proteção de recursos hídricos e recreação (Frischenbruder e Pellegrino 2004). Em escala local, a Rede Verde Urbana para a cidade de Florianópolis (SC) procura melhorar a qualidade dos ambientes urbanizados, favorecendo a interação das espécies da fauna e da flora (Pilotto e Afonso 2004). Em São Luís (MA), Rosa Kliass propõe um sistema de avenidas-parque que ligam áreas livres da cidade. Em escala regional, o projeto Corredores Ecológicos propõe a conexão entre fragmentos de mata atlântica que se estendem da Bahia ao Rio de Janeiro.

Esta pesquisa estudou a viabilidade de implementar corredores verdes que incrementem as condições ecológicas e paisagísticas da cidade. Aliado aos corredores, obteve-se dados que confirmam a possibilidade de integração e melhorias no sistema de praças e parques também para a circulação de pedestres e ciclistas. 


\section{Ambiente conceitual}

A ecologia da paisagem - de onde se extraiu conceitos para o desenvolvimento dos CVUs -, une diversas disciplinas no estudo da paisagem; busca compreender a relação recíproca entre padrões espaciais, fluxos e processos ecológicos (Wu e Hobbs (2002); entende que a paisagem compreende uma área heterogênea onde ecossistemas se repetem e interagem de forma similar (Forman, 1995) e funcionam de acordo com uma dada estrutura que integra aspectos bioecológicos e geoecológicos (Moss, 2000). Assim, baseado em Moss (2000), Hobbs (1997), Baschak e Brown (1995) e Forman (1995), as questões de estrutura, função e mudança são os principais focos do estudo da paisagem em questão.

A estrutura da paisagem é a relação espacial entre elementos da paisagem ou fragmentos (Hobbs 1997). Os componentes estruturais bioecológicos da paisagem são os fragmentos (ecossistemas), corredores e matriz (Forman, 1995), enquanto os geoecológicos são os elementos hidrológicos, pedológicos e geomorfológicos.

Função é a interação entre os elementos espaciais, ou seja, processos hidrológicos, fluxos de partículas, atividades animais e humanas (Forman, 1995), responsáveis por moldar a estrutura da paisagem.

Mudança é a alteração da estrutura e da função ao longo do tempo representada por qualquer alteração na estrutura e/ou função (Hobbs, 1997; Forman e Godron, 1986), decorrentes de processos naturais ou ações humanas, como tempestades, inundações, fogo, transformação do solo etc. (Marsh, 1997).

\subsection{Corredores}

Corredores contribuem com a proteção da biodiversidade, ajudam no gerenciamento das águas, proporcionam oportunidades de recreação, fortalecem a coesão comunitária e cultural, criam identidade, abrigam a circulação da vida silvestre e criam rotas de dispersão (Forman, 1995). Dramstad et al (1996) ressaltam a importância dos corredores como forma de diminuir o isolamento entre fragmentos.

Por serem lineares e estreitos, somente uma gama limitada de espécies adaptadas à exposição à matriz circundante, espécies multihabitat e espécies exóticas invasoras (Forman, 1995) adotam corredores como habitat, com predominância de herbívoros e plantas tolerantes ao sol pleno. Quanto mais largos, estratificados e complexos, maior a biodiversidade observada. Entretanto, a função de habitat não é a principal, mas sim a sua capacidade de funcionar como condutor ou eixo de circulação.

Greenways, ou vias verdes, são tipos especiais de corredor com significância ecológica, recreacional e estética ou que possuam valor histórico e cultural (Fabos 2004) ou outros propósitos compatíveis com o conceito de uso de solo sustentável (Ahern 1995), ou seja, incorporam valores ecológicos e culturais. Outro importante conceito é o de redes verdes (Cook, Fabos, Baschalk etc), que se entende como sistemas interligados de corredores que proporcionam circuitos. Cinco idéias-chave resultam destas definições: linearidade (travessas, ruas, avenidas, passeios, calçadões, passagens ou qualquer elemento linear que sirva a pedestres, ciclistas, veículos diversos e transporte público); conectividade (potencial de ligação entre áreas como praças, parques, bairros, pólos atrativos, dentre outros); multifuncionalidade (multiplicidade de usos tais como circulação, comércio, estar e lazer - e de equipamentos); desenvolvimento sustentável (otimização das condições microclimáticas com a redução da temperatura pelo sombreamento; redução do uso de combustíveis com o uso de bicicletas; retenção de águas pluviais em folhas e galhos e aumento de permeabilidade do solo, reduzindo sobrecargas no sistema de drenagem; retenção de partículas em suspensão nas folhas e absorção de gases conforme Mascaró 
e Mascaró 2002, Hough, 1995; Spirn, 1984); e sistemas lineares integrados (criação de uma rede de mobilidade, conforme Ahern 1995).

\subsection{Corredores Verdes Urbanos (CVUS)}

Analisando-se a cidade conforme a ecologia da paisagem, observam-se fragmentos na forma de praças, parques ou remanescentes de ecossistemas, geralmente cercados por vias e/ou edifícios e, tendo por conseqüência trânsito, polvição, predadores exóticos (cães e gatos), pessoas, entre outros.

Ruas e avenidas são corredores urbanos que atuam como condutores e habitat para seres humanos e espécies animais e vegetais adaptadas ao ambiente urbano, especialmente pássaros. Podem apresentar taxas variadas de arborização e de outros tipos vegetais, entretanto, se corredores em geral apresentam naturalmente uma gama limitada de espécies, na cidade tal leque é ainda mais restrito, podendo ser incrementado com a reestruturação do perfil da malha viária.

Assim como nos greenways, os CVUs buscam múltiplos propósitos, o que inclui objetivos ecológicos, culturais e estéticos e sustentam as cinco idéias-chave mencionadas anteriormente.

\section{Corredores verdes para a cidade de Vitória}

O município de Vitória cobre uma área de aproximadamente $96 \mathrm{~km} 2$, possui população próxima a 310 mil habitantes. Apesar de sua densidade e da perda de recursos naturais decorrente do crescimento da malha urbana, há áreas significativas de vegetação (Figura 1). Vitória mantém bolsões de ambientes naturais de formas distintas em suas porções insular (um grande fragmento central e pequenos fragmentos espalhados) e continental (grandes áreas reflorestadas em grandes empreendimentos do setor secundário, áreas de mangue, parques e praças).

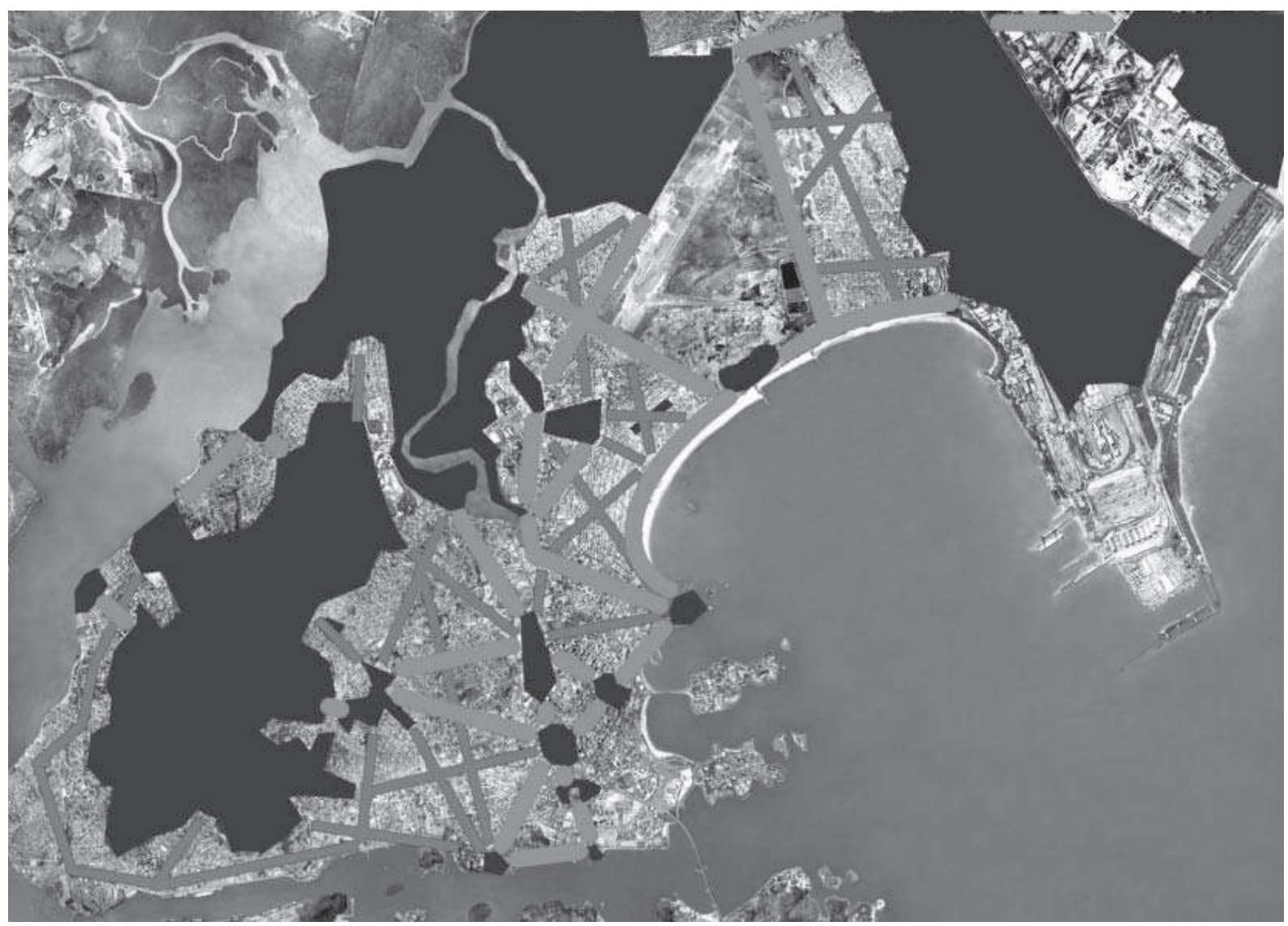

Figura 1: Fragmentos e conceito de conexão 
Percebe-se que ocorrem grandes interrupções de continuidade entre fragmentos, verificando-se, entretanto, áreas com potencial de estabelecimento de uma rede de corredores em duas escalas distintas: a primeira e mais abrangente, de conexão dos grandes fragmentos continentais entre si e destes com o fragmento insular; a segunda concerne à ligação entre fragmentos menores apropriando-se da estrutura viária.

\section{1. Área teste}

Para explorar os conceitos de CVUs e visando avaliar a metodologia adotada foi selecionada uma área teste compreendendo vários bairros na parte continental da cidade (Figura 2), sendo estabelecidas as seguintes etapas de trabalho:

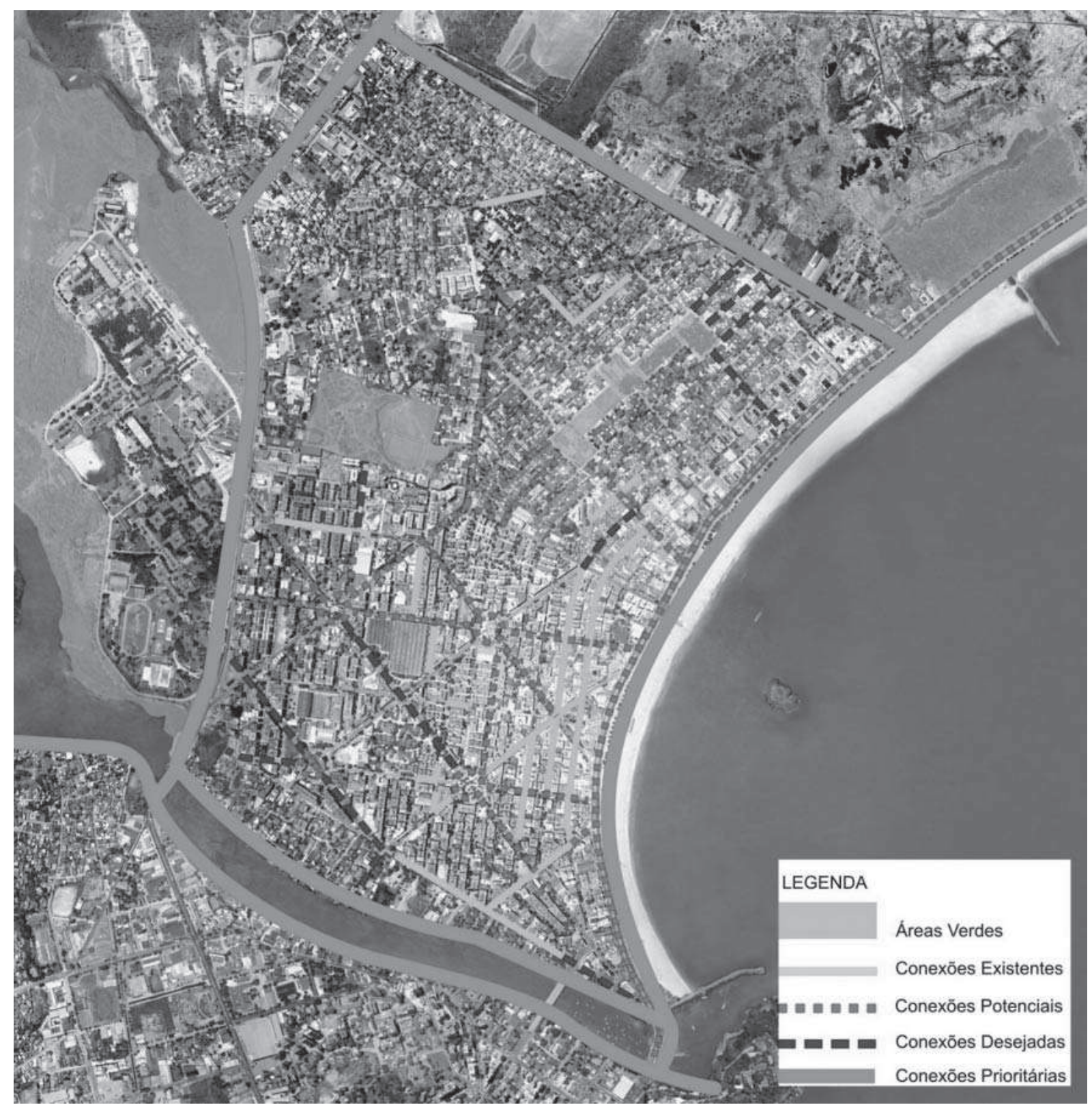

Figura 2: Vias selecionadas e sua classificação

\subsubsection{Levantamentos preliminares}

Consultas à bibliografia, documentos, mapas, fotografias, planos e projetos, periódicos e outros, sendo as informações registradas através de desenhos e mapas que ampararam a análise das 
áreas e o desenvolvimento dos ensaios projetuais. Destacam-se na área teste, o grande número de habitantes; a ambiência tradicional de pedestres; áreas verdes; proximidade de áreas de interesse ecológico-ambiental; pólos atrativos (praia de Camburi, Universidade Federal do Espírito Santo, equipamentos culturais, escolas, supermercados, centros comerciais e praças); e grandes eixos de circulação.

\subsubsection{Mapeamento de áreas verdes}

Foram identificadas as áreas verdes existentes ou potenciais através de fotografias aéreas, mapas e visitas exploratórias, sendo consideradas aquelas que possuem vegetação significativa, em especial arbórea, ou potencial para desenvolvimento de vegetação. Consideraram-se áreas verdes praças, parques, orlas, remanescentes de ecossistemas em áreas públicas ou privadas, destacando-se:

- Mangues da UFES: grande área de manguezal, Mata Atlântica, vegetação rupestre, mata de tabuleiro e vegetação de transição transformada em área de conservação;

- Parque Municipal Pedra da Cebola: parque urbano com grandes espaços abertos, utilizados como local de lazer e ligação para pedestres entre bairros e o Campus da UFES;

- Parque Municipal no bairro Mata da Praia: cinco praças retangulares contíguas, com equipamentos de lazer, esporte, educação ambiental e área de restinga que conserva espécies nativas da região e atrai a fauna local; e

- Reserva Ecológica Municipal Restinga de Camburi: remanescente de restinga de aproximadamente 12 ha.

\subsubsection{Seleção de vias}

Após o mapeamento das áreas verdes, foram identificadas as vias que apresentaram condições de conexão através da leitura de fotografias aéreas e mapas, seguida pela realização de visitas exploratórias para confirmação das informações.

\subsubsection{Avaliação das vias}

Para as vias passíveis de abrigar CVUs avaliou-se: 1) valores: de uso (circulação de pedestres e ciclistas, potencial de socialização), ecológicos, de recreação, históricos e culturais; 2) potencial de conexão; 3) estrutura física (espaço para arborização, larguras de calçadas, canteiros e leito, instalações de eletricidade e telefonia; 4) qualidade e diversidade dos elementos naturais (flora, água, ar, fauna); e 5) apropriação pelas comunidades do entorno.

As vias foram classificadas de acordo com as condições verificadas in loco e com a seguinte conceituação:

Prioritárias: vias necessárias para efetivar a conexão entre grandes fragmentos ou entre vias com grande capacidade de abrigar o corredor e que apresentem condições ambientais que indiquem a necessidade prioritária de intervenção. Sua identificação ocorre primordialmente através de fotografias aéreas por permitirem a visualização abrangente da paisagem.

Existentes: são as que já apresentam cobertura vegetal densa.

62 Potenciais: são vias que ligam fragmentos, fragmentos com corredores ou corredores com outros corredores e que podem contribuir para estabelecer uma rede de corredores.

Desejadas: vias que podem acrescentar alguma conexão desejável e que venha a conectar, por exemplo, pólos de atração ou pequenas áreas verdes à rede. 


\subsubsection{Inventário}

Os condicionantes físicos (estrutura geológica, clima, hidrologia), bioecológicos (fauna e flora) e culturais (relacionados a atividades ou produtos de atividades humanas) das áreas verdes e vias selecionadas foram levantados através de visitas às áreas e os dados obtidos registrados em fotografias, mapas, plantas, relatórios e fichas.

Percebeu-se uma baixa biodiversidade vegetal. Segundo Milano et al (1992), 66,9\% das árvores são de três espécies e apenas 35\% da área urbanizada de Vitória pode ser considerada como arborizada, enquanto 34\% da área não possui qualquer arborização, ressaltando-se tratar de dados de 1992, embora a realidade do lugar parece ter continuado semelhante. Apesar do difícil registro e identificação da fauna, observações permitiram identificar algumas espécies nas ruas de Vitória, tais como lagartos, corujas, bem-te-vis, cará-carás, viuvinhas, sabiás, araras, periquitos, gambás e sagüis.

\subsubsection{Análise}

Com o intuito de estabelecer parâmetros para os ensaios projetuais, a análise das vias revelou uma gama ampla de tipos de vias, como pode ser constatado nas Figuras 3 a 6 . Foram registradas, nas fotos aéreas, as diversas categorias, obtendo-se um panorama da complexidade e das diferentes condições do sistema, que gerando um quadro síntese de tipologia viária.

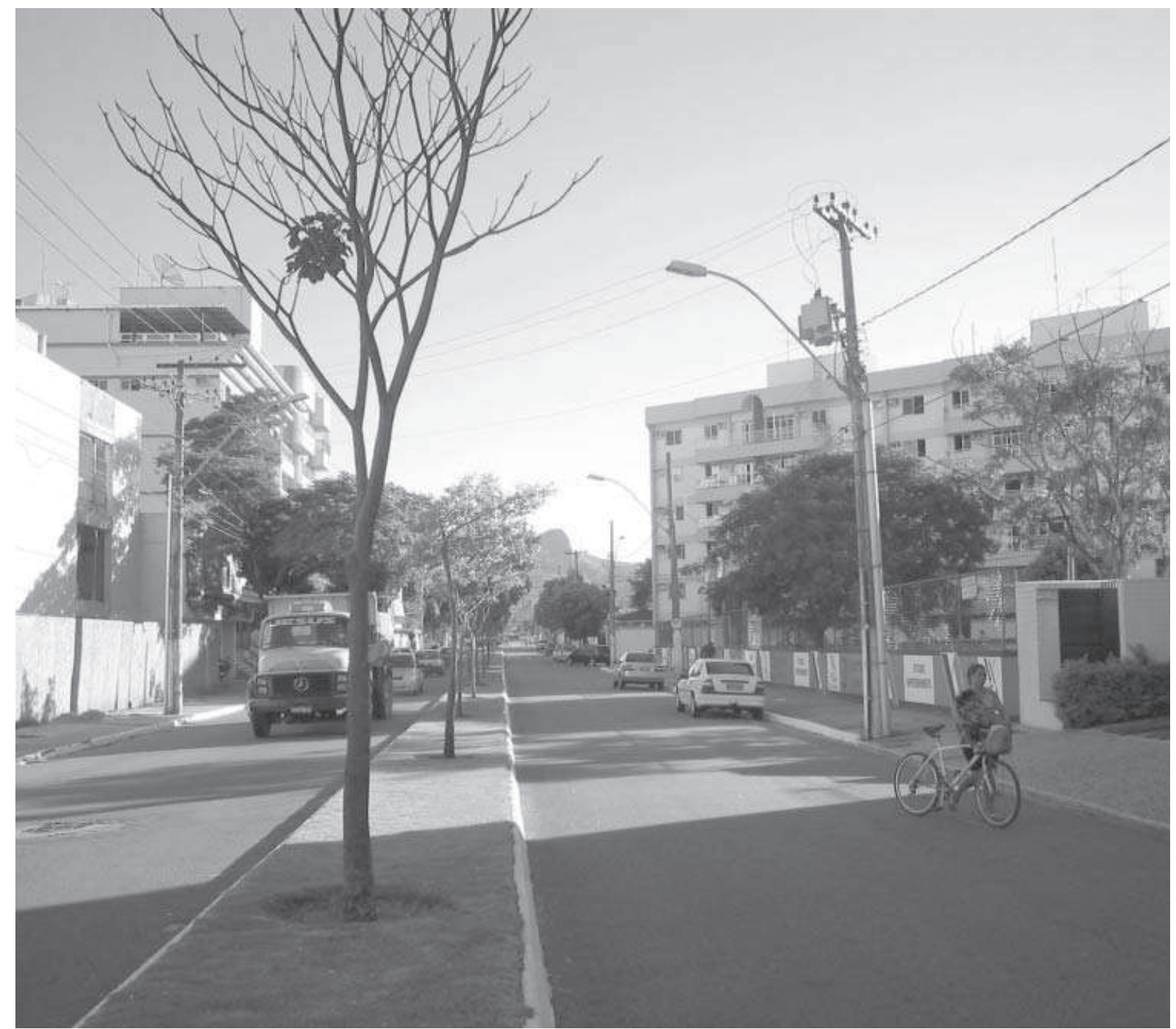

Figura 3: Avenida com quatro pistas e arborização esparsa 


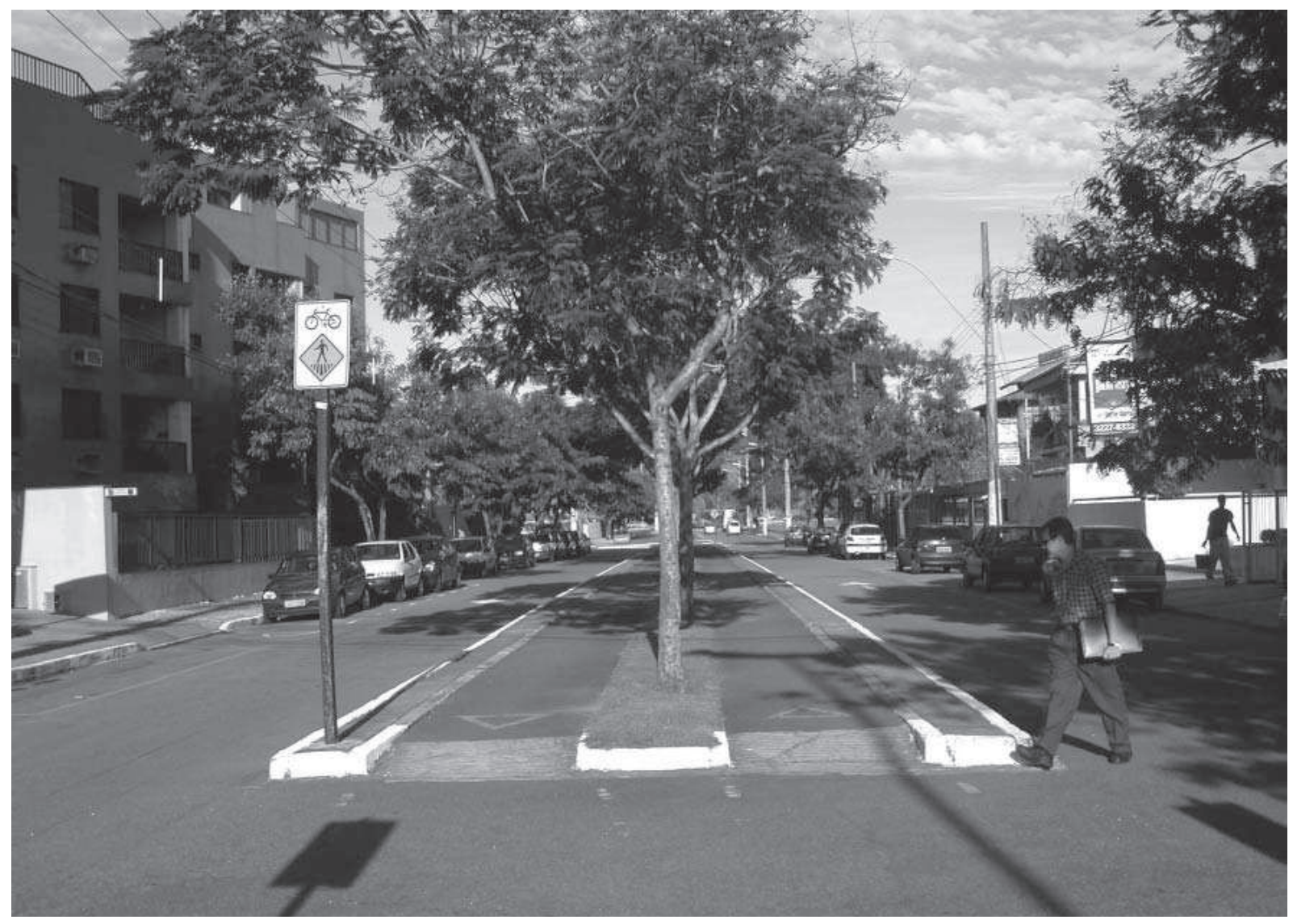

Figura 4: Avenida com quatro pistas e ciclovia central, bem arborizada, mas com interrupções

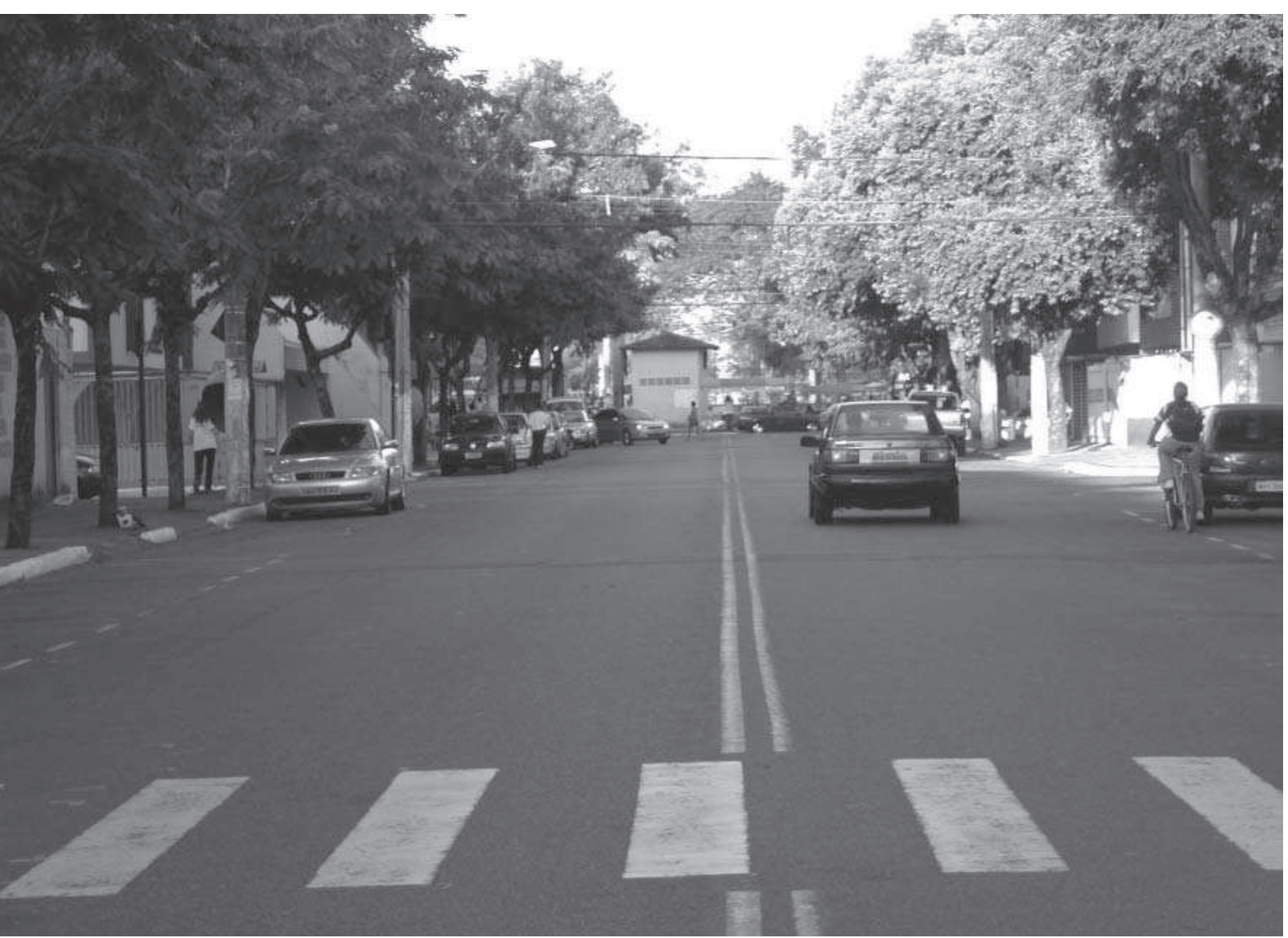

Figura 5: Avenida sem canteiro central, bem arborizada 


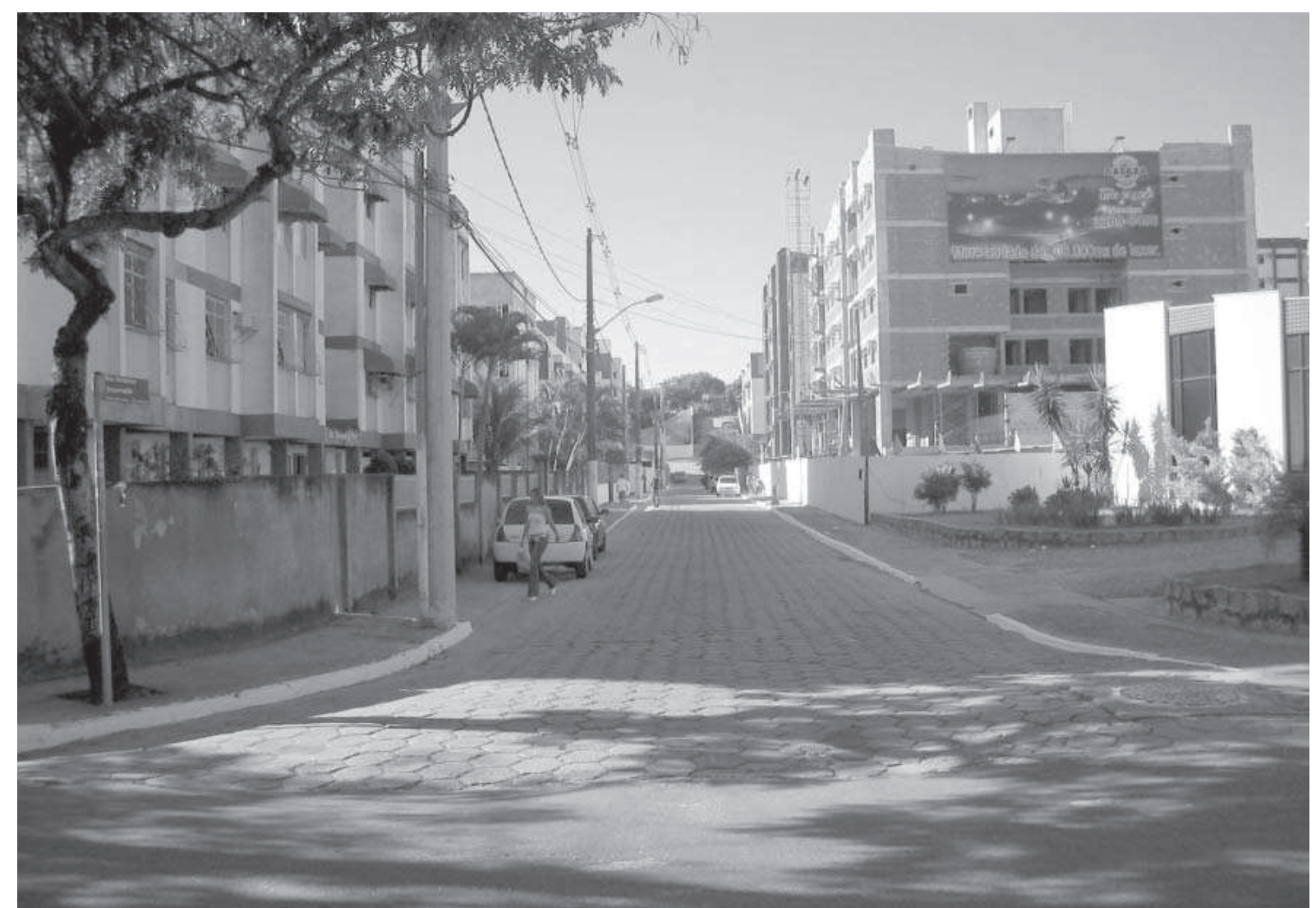

Figura 6: Rua estreita e sem vegetação

\subsubsection{Diretrizes}

A definição dos CVUs respeitou as seguintes diretrizes:

- Implementação de calçadas confortáveis e aplicação dos princípios da Calçada Cidadã propostos pela Prefeitura Municipal de Vitória, dando condições de acessibilidade plena (desenho universal);

- Determinação de faixas exclusivas para ciclistas;

- Ampliação da arborização, com copas contínuas e diversidade de espécies resistentes ao ambiente urbano, que produzam sombra, frutos atrativos para fauna e tenham folhas que contribuam na retenção de partículas; e

- Criação de travessias de pedestres seguras.

\subsubsection{Ensaio projetual}

Para as áreas que apresentaram viabilidade para estabelecimento de CVUs foram elaborados cortes, plantas, perspectivas e simulações fotográficas onde se avalia sua aos objetivos do estudo. Os ensaios também servem de instrumento de análise, possibilitando identificar os potenciais e as limitações das áreas investigadas, como demonstrado nas Figuras 7 a 9.

Nos locais em que ruas e calçadas são estreitas, propõe-se a reformulação das calçadas de forma a permitir um incremento na arborização. Em avenidas de quatro pistas é comum encontrar carros estacionados sobre a faixa da direita, indicando a possibilidade de assumir tais áreas como estacionamento e eliminar a faixa de rolamento. Com isso, pode-se ampliar as calçadas e reservar áreas para implantação de equipamentos públicos e mobiliário urbano, tais como bancos, lixeiras, caixas de correio, bancas de jornais e bicicletários (Figura 7). 

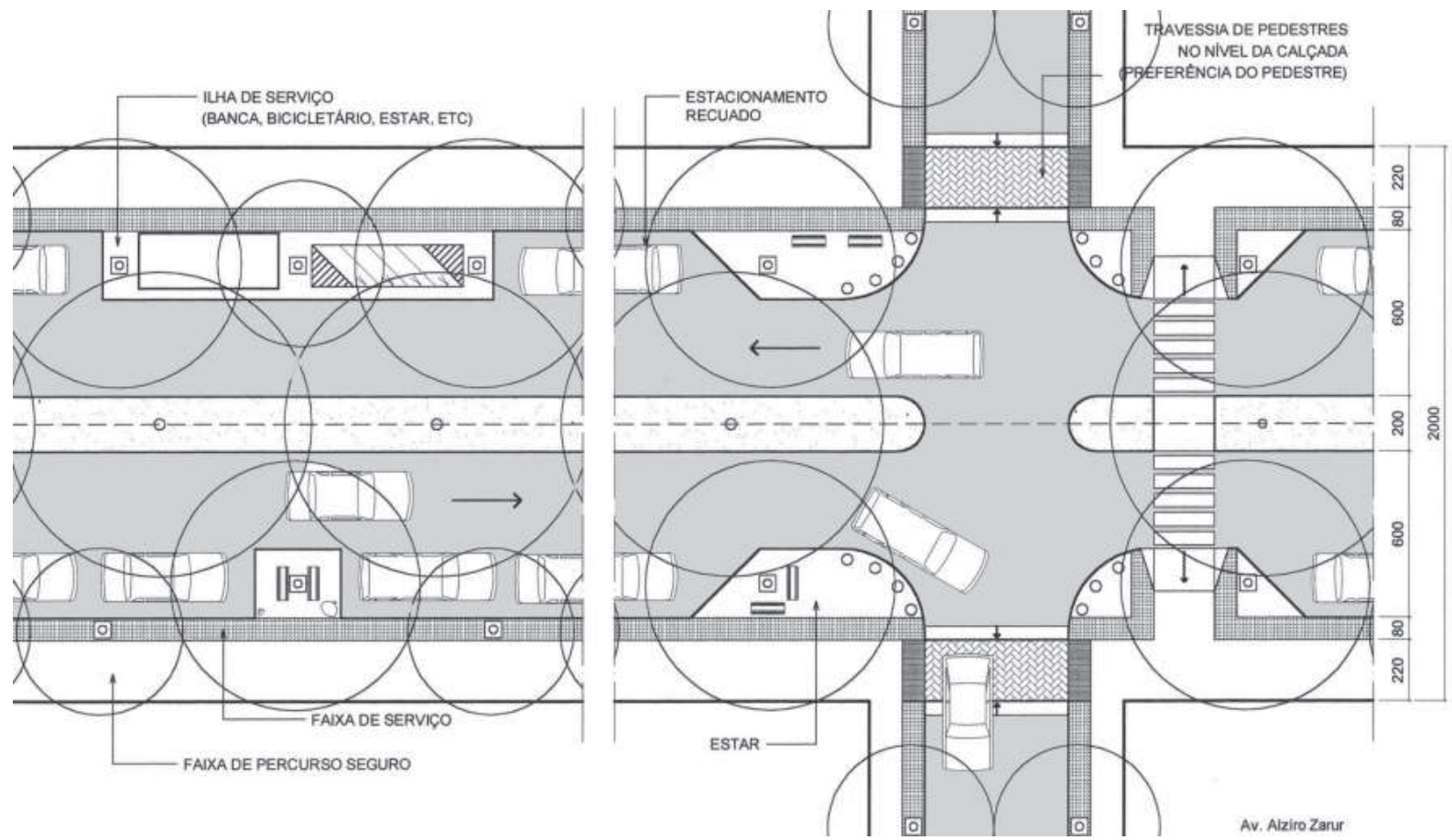

Figura 7: Proposta de reformulação da via com incremento da vegetação; Calçada Cidadã, com passagem nivelada nas faixas de pedestre e equipamentos urbanos

A Avenida Hugo Viola (Figura 3) possui calçadas de aproximadamente 1,50 m em ambos os lados e quatro pistas de rolamento, sendo o fluxo concentrado nas pistas centrais e as pistas à direita utilizadas como estacionamento em alguns trechos. Apresenta segmentos com canteiro central densamente arborizado e movimento médio de veículos. Propõe-se manter uma faixa de estacionamento ao longo da calçada e reservar uma faixa demarcada para ciclistas junto à faixa de rolamento (Figura 8). Já a Figura 9 apresenta um modelo para rua sem saída com implementação de vegetação e equipamentos urbanos adequados ao tipo de uso previamente verificado.

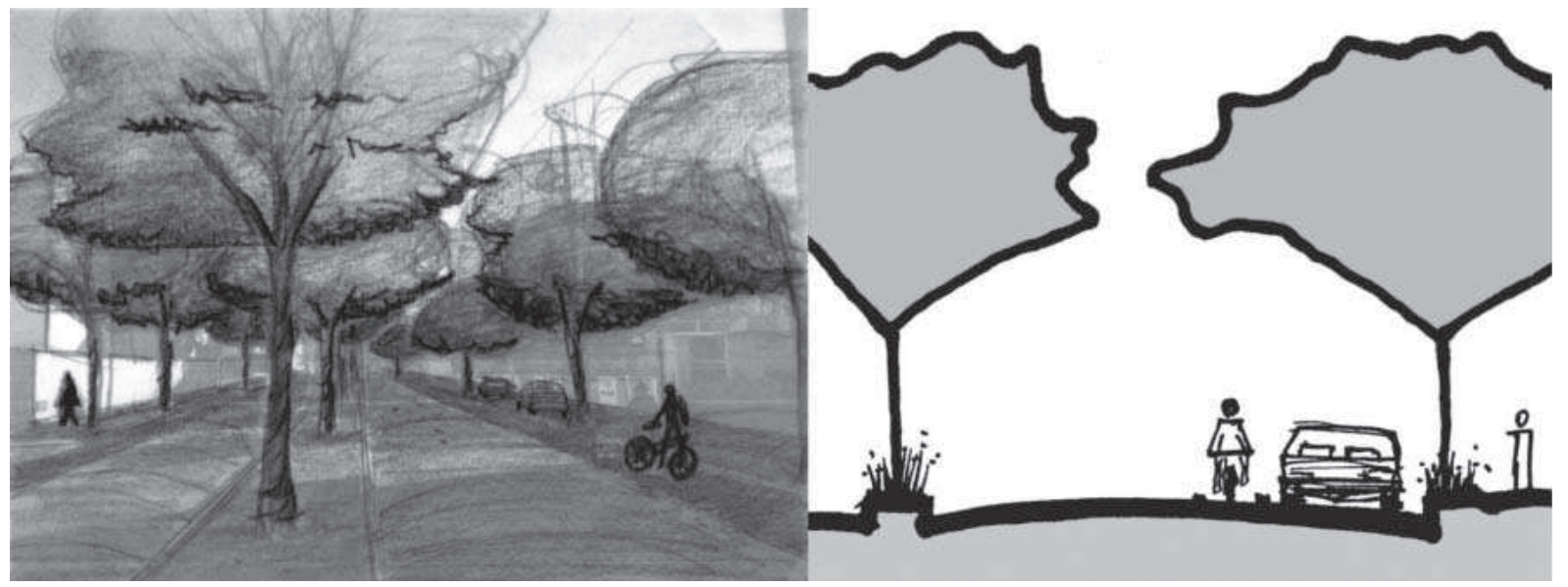

Figura 8: Proposta para a avenida Hugo Viola

\subsubsection{Resultados finais}

No ensaio projetual verificou-se que a conformação da estrutura viária e fundiária dificultou a elaboração de propostas em função das seguintes características: 
- Espaço disponível x programa de necessidades: as calçadas e as áreas dos estacionamentos de veículos não são suficientes para a implementação de ciclovias, arborização, estacionamentos e vias adequadas para pedestres;

- Fiação: fios aéreos atrapalham a colocação de árvores em ambos os lados da rua;

- Cultural: eventual despreparo da população para aceitação, do modelo proposto.

No entanto, mesmo diante de tais dificuldades, com o lançamento das propostas projetuais pontuais verificou-se que salutar relação custo x benefício, especialmente considerando a densidade atual da área teste e da cidade em geral.

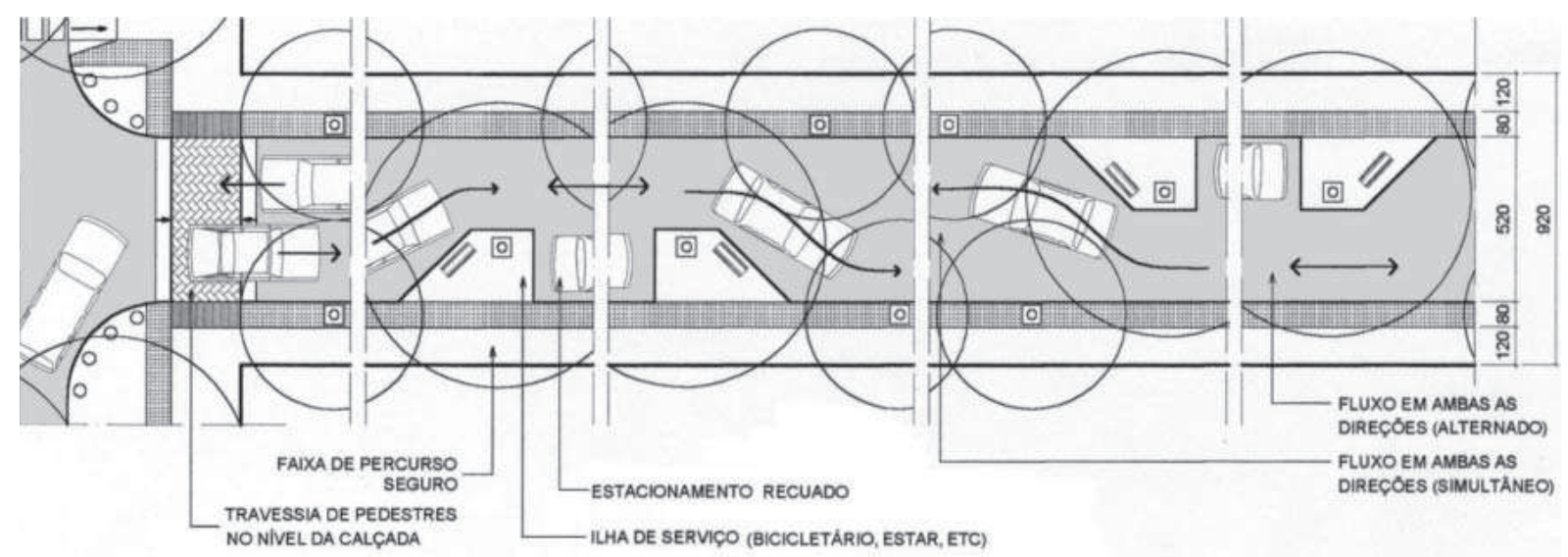

Figura 9: Rua sem saída: estreitamento do leito e "penínsulas" para implantação de vegetação

\section{Avaliação dos resultados}

As dificuldades verificadas na área teste obrigaram ao enfrentamento de questões complexas que também se repetiriam nos demais cenários da cidade. A questão da fiação aérea, por exemplo, é um impeditivo que poderia ser sanado com a utilização de redes subterrâneas, como já ocorre em alguns locais da cidade, cujos ganhos estéticos e possibilidades de ampliação da cobertura vegetal certamente compensarão os custos iniciais de investimento.

Conforme afirmam Baschak and Brown (1995), alguns elementos existentes na paisagem devem ser modificados para estabelecer uma rede ecológica dentro de uma infra-estrutura urbana já estabelecida. No caso específico das características referentes às vias, especialmente as dimensionais, exigem que para a concretização dos corredores, sejam tomadas medidas pouco usuais. Tome-se como exemplo a consolidação de ciclovias quando muitas vezes não há espaço suficiente para sua implantação, mas há condições para demarcar uma faixa dedicada a bicicletas no leito da rua. Tal medida demandaria ações educacionais intensivas e uma mudança do paradigma hoje vigente de que o carro possui o privilégio de tráfego. Entretanto, tal medida obteve sucesso em outros países, sendo comum a convivência harmônica entre ciclistas e motoristas. Mesmo no Brasil percebe-se que as primeiras cidades que implementaram o atual código de trânsito, acompanhado de forte campanha educativa e de divulgação - como Brasília, por exemplo -, hoje possuem uma saudável relação entre pedestre e motoristas.

Conclui-se que, apesar das dificuldades, o teste metodológico identificou a possibilidade de criação dos CVUs na estrutura viária e fundiária da área estudada exigindo, no entanto, transformações na mesma que resultariam em amplos ganhos ambientais, sendo os usuários, os grandes beneficiados. 


\section{Bibliografia}

BASCHAK, Lawrence; BROWN, Robert D. An ecological framework for planning and management of urban river greenways. Landscape and Urban Planning, n. 33, p. 211-225, 1995.

BRYANT, Margaret. Urban landscape conservation and the role of ecological greenways at local and metropolitan scales. Landscape and Urban Planning, 2004.

COOK, Edward A. Urban landscape networks: An ecological framework. Landscape Research, v. 3, n. 16, p. 7-15, 1991.

DRAMSTAD et al. Landscape ecology principles in landscape architecture and land-use planning. Wahsington, DC: Island Press and ASLA, 1996.

FORMAN, Richard T. T. Land mosaics - The ecology of landscapes and regions. Cambridge: University Press, 1995. ; GODRON, Michel. Landscape ecology. Nova York: John Wiley and Sons, 1986.

Patches and structural components for landscape ecology. BioScience, v. 31, n. 10, p. 733-740, 1981.

FRISCHENBRUDER; PELLEGRINO. Using greenways to reclaim nature in brazilian cities. Landscape and Urban Planning, 2004.

HOBBS, Richard. Future landscapes and the future of landscape ecology. Landscape and Urban Planning, n. 37, p. 1-9, 1997.

HOUGH, Michael. Cities and natural process. Nova York: Routledge, 1995.

MARSH, William M. Landscape planning - Environmental applications. $3^{\text {rd }}$ Ed. ed. John Wiley and Sons. Nova York, 1997.

MASCARÓ, Lucia R.; MASCARÓ, Juan. Vegetação urbana. Porto Alegre. Finep/UFRGS, 2002.

PILOTTO, Jane; AFONSO, Sonia. A rede verde urbana aplicada no município de Florianópolis, SC. In: VII ENEPEA, Anais..., Florianópolis-SC, 2004

SPIRN, Ann. Granite garden. Nova York: Basic Books, 1984.

WU, Jianguo; HOBBS, Richard. Key issues and research priorities in landscape ecology: An idiosyncratic synthesis. Landscape Ecology, n. 17, p. 355-365, 2002. 